\title{
Moderating effects of coping on work stress and job performance for nurses in tertiary hospitals: a cross-sectional survey in China
}

\author{
Li Li $i^{1^{*}}$, Hua Ai ${ }^{2}$, Lei Gao ${ }^{1}$, Hao Zhou ${ }^{3}$, Xinyan Liu' ${ }^{1}$ Zhong Zhang ${ }^{1}$, Tao Sun ${ }^{1 *}$ and Lihua Fan ${ }^{1 *}$
}

\begin{abstract}
Background: Work stress is a major problem for nurses and it can negatively influence job performance. Therefore, it is critical to explore variables that can reduce or buffer the negative effects of work stress. This study explores the moderating effects of coping strategies on the relationship between work stress and job performance for nurses in China.

Methods: A cross-sectional survey of 852 nurses from four tertiary hospitals in Heilongjiang Province, China, was conducted in 2013. Descriptive statistics were reported for socioeconomic status and demographic characteristics, level of work stress, coping strategies, and job performance. Regression analysis was conducted to test the interaction between work stress and coping strategies on job performance.

Results: Three subscales of work stress were negatively related to job performance. Positive coping strategies moderated Patient Care and job performance while negative coping strategies moderated Workload and Time and performance, and between Working Environment and Resources and performance.
\end{abstract}

Conclusions: Positive coping strategies reduce or buffer the negative effects of work stress on job performance and negative coping strategies increased the negative effects.

Keywords: Coping, Nurses, Work stress, Job performance, Moderation

\section{Background}

Worldwide, nursing is known to be a very stressful occupation. Studies from China reported that nurses work under great pressure because of a heavy workload, contending with death and dying, inter-staff conflict, lack of resources, and insufficient training [1]. Long term stress may affect hospitals through nurses' dissatisfaction, burnout, poor performance, or turnover intention [2-5]. Since nurses are the frontline staff of the healthcare team this can reduce the quality of health services. Therefore, it is important for both nurses and their managers to take measures to reduce work stress.

\footnotetext{
* Correspondence: healthlaw@126.com; hydsuntao@126.com; lihuafan@126.com

${ }^{1}$ Department of Health Management, School of Public Health, Harbin Medical University, Baojian Road 157, Harbin, China

Full list of author information is available at the end of the article
}

Work stress can be defined as a mismatch between an individual and their environment [6]. In general, the higher the imbalance between external demands and an individual's abilities, the higher the level of stress that will be experienced [7].

In recent years, there has been a substantial amount of research on the relationship between work stress and job performance. Some of this research revealed that high work stress lead to low job performance [2]. However, a few studies found an inverted U-shaped relationship or a positive relationship between work stress and job performance $[8,9]$. Wu et al. asserted that a possible explanation for these inconsistent results might be existing variables to moderate the effect of stress on performance [10]. A broad range of variables have been considered as potential moderators such as emotional intelligence, organizational commitment, and supportive leadership 
[11, 12]. Folkman's study showed that effective coping strategies can avoid or reduce stress levels [13].

According to the Transactional Model of Stress, coping is an integral element in the stress process because coping strategies can help alleviate the effects of stressors on strains [14].

Previous studies have identified two main types of coping strategies: emotion-focused and problem-focused strategies [13]. Later analyses subdivided emotional-focused strategies into escape-avoidance, distancing, self-control, and positive reappraisal [15]. Other researchers have categorized coping strategies into positive or constructive coping and negative or destructive coping [16].

Recent research revealed that coping strategies played an important moderating role in work stress and well-being as well as job satisfaction among nurses and administrators $[17,18]$. However, there continues to be a lack of information on the moderating effects of coping strategies on work stress and job performance for Chinese nurses.

Based on the Transactional Model of Stress, the aim of this study was to examine the moderating effects of coping strategies on work stress and job performance. Specifically, we explore: (a) the levels of work stress, coping strategies, and job performance that occurs in nursing; (b) the associations among stress, coping strategies, and job performance; and (c) whether coping strategies moderate the relationship between work stress and job performance.

\section{Methods}

\section{Sample}

A cross-sectional questionnaire survey was conducted in Heilongiiang Province, China, from September 2013 to December 2013. Two tertiary university-affiliated hospitals and two tertiary non-affiliated hospitals were selected. There were 8-10 types of clinical departments in these four hospitals. One sub-department was randomly selected in each kind of clinical department in each hospital. The data were collected anonymously and the participants completed the questionnaires privately to ensure confidentiality. The questionnaire included a cover page explaining the purposes and procedures of the study. Respondents were assured that participation in the survey was voluntary, and the return of questionnaires represented informed consent. Nurses who take part in the survey were able to choose the best time to complete the questionnaire. Most questionnaires were collected on site by the investigator on the day of the visit. If some nurses did not finish that day, investigators set a date to retrieve the questionnaires. The questionnaire was relatively brief and no private personal information was collected. In total, 1057 questionnaires were distributed and 1027 questionnaires were returned for a response rate of $97.2 \%$. However, 175 were incomplete or even blank, which left 852 (80.6) valid questionnaires. This study was approved by Medical Ethic Committee of Harbin Medical University.

\section{Assessment tools Job performance scale}

In this study, we used a 5-item scale developed by Williams and Anderson to examine in-role job performance (e.g. "I effectively fulfilled my roles and responsibilities concerning the hospital's proposal assignment") [19, 20]. This self-report tool asked participants to rate their responses on a 7-point scale ranging from 1 (highly disagree) to 7 (highly agree). Then, scores were averaged across items to form a scale score. In terms of reliability, the Cronbach's alpha of the task performance scale in the present study was 0.85 . The result of correlation test showed that there was a significant correlation between the averaged scores and individual score of five items, which proved to be of good validity (correlation $=0.47-0.75$ ).

\section{Work stress scale}

Taking into consideration the Chinese cultural background of participants and acceptable reliabilities of available instruments, work stress was measured with a 35-item scale developed by Li and Liu which named Chinese Nurse Job Stressors Questionnaire (e.g. "few opportunities for improvement") [21]. This scale is composed of five subscales (i.e., Nursing Profession and Clinical Duty, Workload and Time, Working Environment and Resources, Patient Care, and Management and Interpersonal Relationship). Respondents were asked to indicate the strength of their agreement with the statements on a 4-point scale ranging from 1 (highly disagree) to 4 (highly agree). The scale achieved reasonable reliability in our sample, obtaining an overall Cronbach's alpha of 0.92. In addition, the Cronbach's alpha for the individual scales ranged from 0.81 to 0.88 . Scores of 35items were averaged to form the general work stress scores. We identified the general work stress as criterion validity. The result of correlation test showed that there was a significant correlation between five subscales of work stress and the general work stress. (Correlation $=0.39-0.76)$.

\section{Coping strategies scale}

The 20-item version of the Simple Coping Style Scale, which was developed by Xie was used to examine coping strategies used by nurses [22]. The scale classified coping strategies into positive coping (12 items) (e.g. "looking for support from family or friends, utilizing others' ways of dealing with similar problems") and negative coping (8 items) (e.g. "procrastinating, relying on others, trying to forget about everything"). Respondents were asked to indicate the frequency that they used each strategy with a 4-point scale ranging from 0 (never used) to 3 (often 
used). In the present study, the scale demonstrated appropriate reliability and the Cronbach's alpha was 0.86 . Scores of 20 items were averaged to form a scale score. We identified the scale score as criterion validity. The result of correlation test showed that there was a significant correlation between positive coping strategies, negative coping strategies and the scale score. (Correlation $=0.29-0.74)$.

\section{Data analysis}

In this study, survey results were analyzed using SPSS V.19.0. There were four main components to the data analysis. First, descriptive statistics were reported for socioeconomic and demographic status, work stress, coping strategies, and job performance. Second, correlations among work stress, coping strategies, and job performance were assessed using correlational analysis. Third, regression analysis was conducted to test potential moderating effects [23]. Centered scores were used for the interaction terms to avoid multicollinearity. Finally, significant interactions were explored by examining conditional effects with contrasts and plots, and simple effects tests were conducted to determine whether the slopes significantly differed from zero. A $p$-value of 0.05 was considered to have statistical significance.

\section{Results}

\section{Description of respondents}

Table 1 reports participants' socioeconomic and demographic characteristics. Participants were predominantly female $(96.6 \%)$ and had attained a bachelor's degree (63.8\%). Only $5.7 \%$ had a senior professional title. The average age was 28 years and $87.7 \%$ of respondents were under 35 years of age. About $80 \%$ had worked less than 10 years in their current position. In terms of marital status, $45.5 \%$ were married and $54.5 \%$ were single, separated, or divorced.

From Table 2 it can be seen that Nursing Profession and Clinical Duty $(\mathrm{M}=3.17, \mathrm{SD}=0.62)$ emerged as the major stressor, followed by Workload and Time $(M=2.93$, $\mathrm{SD}=0.61)$, Working Environment and Resources $(\mathrm{M}=2.67, \mathrm{SD}=0.77)$, Patient Care $(\mathrm{M}=2.55, \mathrm{SD}=0.63)$, and Management and Interpersonal Relationship $(\mathrm{M}=2.46, \mathrm{SD}=0.61)$. Mean scores of positive and negative coping strategies were $1.98(\mathrm{SD}=0.55)$ and 1.37 , respectively. Results also indicated the average level of job performance was 5.64 $(\mathrm{SD}=0.59)$.

\section{Correlations among the study variables}

The correlations among the study variables are presented in Table 2. Each subscale of work stress had a significant negative correlation with job performance and positive coping strategies $(r=-0.09$ to $-0.52, p<0.01)$ and a significant positive correlation with negative coping
Table 1 Demographic characteristics of respondents $(N=852)$

\begin{tabular}{|c|c|c|}
\hline \multicolumn{2}{|l|}{ Variables } & \multirow{2}{*}{$\frac{N(\%)}{822(96.5)}$} \\
\hline Gender & Female & \\
\hline \multirow[t]{4}{*}{ Age in years } & $<25$ & $242(28.4)$ \\
\hline & $25-34$ & $502(58.9)$ \\
\hline & $35-44$ & $76(8.9)$ \\
\hline & $\geq 45$ & $32(3.8)$ \\
\hline Mean age & $28.20 \pm 6.85$ & \\
\hline \multirow[t]{2}{*}{ Marital status } & Married & $388(45.5)$ \\
\hline & Others & $457(54.5)$ \\
\hline \multirow[t]{4}{*}{ Educational level } & Secondary technical certificate & $20(2.4)$ \\
\hline & Associate degree & $271(31.8)$ \\
\hline & Bachelor's degree & $544(63.8)$ \\
\hline & Master's degree & $17(2.0)$ \\
\hline \multirow[t]{5}{*}{ Professional title } & Nurse & $393(46.1)$ \\
\hline & Nurse Practitioner & $290(34.0)$ \\
\hline & Nurse-in-charge & $121(14.2)$ \\
\hline & Associate professor of nursing & $32(3.8)$ \\
\hline & Professor of nursing & $16(1.9)$ \\
\hline \multirow[t]{4}{*}{ Administrative position } & Nursing assistant & $24(2.8)$ \\
\hline & Clinical nurse & $692(81.3)$ \\
\hline & Group leader nurse & $77(9.0)$ \\
\hline & Head nurse & $59(6.9)$ \\
\hline \multirow[t]{5}{*}{ Monthly income (RMB) } & $\leq 2000$ & $52(6.1)$ \\
\hline & $2001-4000$ & $453(53.2)$ \\
\hline & $4001-6000$ & $289(33.9)$ \\
\hline & $6001-8000$ & $41(4.8)$ \\
\hline & $>8000$ & $17(2.0)$ \\
\hline \multirow[t]{4}{*}{ Tenure (years) } & $<5$ & $471(55.3)$ \\
\hline & $6-10$ & $205(24.1)$ \\
\hline & $11-15$ & $82(9.6)$ \\
\hline & $\geq 16$ & $94(11.0)$ \\
\hline
\end{tabular}

strategies $(r=0.09 \sim 0.23, p<0.01)$. In addition, positive coping strategies were positively correlated with job performance $(r=0.28, p<0.01)$ and negative coping strategies were negatively correlated with job performance $(r=-0.14, p<0.01)$.

\section{Testing direct effects and moderating effects}

Table 3 demonstrates the three models used to test the direct effect and moderating effects of work stress and coping strategies on job performance. In Model 1, the inclusion of the five work stress subscales resulted in Nursing Profession and Clinical Duty, Workload and Time, and Management and Interpersonal Relationship as negative predictors of job performance (adjusted $\left.\mathrm{R}^{2}=0.36, p<0.01\right)$. In Model 2 , the inclusion of five work stress subscales and coping strategies resulted in 
Table 2 Means, standard deviations (SD), and correlations among work stress, coping strategies and job performance

\begin{tabular}{|c|c|c|c|c|c|c|c|c|c|}
\hline & Mean & SD & 1 & 2 & 3 & 4 & 5 & 6 & 7 \\
\hline 1. Management and Interpersonal Relationship & 2.46 & 0.61 & & & & & & & \\
\hline 2. Nursing Profession and Clinical duty & 3.17 & 0.62 & $0.283^{*}$ & & & & & & \\
\hline 3. Workload and Time & 2.93 & 0.61 & $0.474^{*}$ & $0.595^{*}$ & & & & & \\
\hline 4. Patient Care & 2.55 & 0.63 & $0.539^{*}$ & $0.227^{*}$ & $0.374^{*}$ & & & & \\
\hline 5. Working Environment and Resources & 2.67 & 0.77 & $0.481^{*}$ & $0.348^{*}$ & $0.433^{*}$ & $0.369^{*}$ & & & \\
\hline 6. positive coping & 1.98 & 0.55 & $-0.211^{*}$ & $-0.089^{*}$ & $-0.180^{*}$ & $-0.131^{*}$ & $-0.089^{*}$ & & \\
\hline 7. negative coping & 1.37 & 0.67 & $0.229^{*}$ & $0.080^{*}$ & $0.089^{*}$ & $0.218^{*}$ & $0.181^{*}$ & $0.153^{*}$ & \\
\hline 8. job performance & 5.64 & 0.59 & $-0.522^{*}$ & $-0.387^{*}$ & $-0.413^{*}$ & $-0.321^{*}$ & $-0.404^{*}$ & $0.279^{*}$ & $-0.142^{*}$ \\
\hline
\end{tabular}

${ }^{*} P<0.01$

three subscales of work stress (i.e. Nursing Profession and Clinical Duty, Workload and Time, and Management and Interpersonal Relationship). In addition, negative coping strategies were negative predictors, while positive coping strategies were positive predictors of job performance (adjusted $\mathrm{R}^{2}=0.41, P<0.01$ ).

Model 3 augmented Model 2 through inclusion of the interaction terms (Work Stress $\times$ Coping Strategies). We found that positive coping strategies moderated the relationship between Patient Care and job performance $(\beta=0.44, P<0.01)$. Negative coping strategies moderated the relationship between Workload and Time and job performance $(\beta=-0.47, P<0.01)$, and the relationship between Working Environment and Resources and job performance $(\beta=-0.53, P<0.05)$.

The significant moderations were probed following the procedures recommended by Aiken and West [24]. The values of the moderators (positive coping strategies and negative coping strategies) were chosen $1 \mathrm{SD}$ above and 1 $\mathrm{SD}$ below the mean to form simple regression equations.

Table 3 Regression analysis for testing moderation effects of coping on work stress and job performance

\begin{tabular}{|c|c|c|c|c|c|c|}
\hline \multirow[t]{2}{*}{ Variables } & \multicolumn{2}{|c|}{ Model 1} & \multicolumn{2}{|c|}{ Model 2} & \multicolumn{2}{|c|}{ Model 3} \\
\hline & $\bar{\beta}$ & $p$ & $\beta$ & $p$ & $\bar{\beta}$ & $p$ \\
\hline \multicolumn{7}{|l|}{ Subscales of work stress } \\
\hline Nursing profession \& clinical duty & -0.39 & 0.00 & -0.32 & 0.00 & -0.31 & 0.04 \\
\hline Workload \& time & -0.19 & 0.00 & -0.25 & 0.00 & -0.51 & 0.00 \\
\hline Working environment \& resources & -0.06 & 0.12 & -0.06 & 0.11 & 0.34 & 0.04 \\
\hline Patient care & -0.00 & 0.97 & 0.03 & 0.44 & -0.42 & 0.00 \\
\hline Management \& interpersonal relationship & -0.12 & 0.00 & -0.10 & 0.00 & 0.16 & 0.25 \\
\hline \multicolumn{7}{|l|}{ Subscales of coping strategies } \\
\hline Positive coping strategies & & & 0.24 & 0.00 & 0.22 & 0.00 \\
\hline Negative coping strategies & & & -0.12 & 0.00 & -0.16 & 0.00 \\
\hline \multicolumn{7}{|l|}{ Subscales of work stress $\times$ coping strategies } \\
\hline Nursing Profession and Clinical Duty $\times$ positive coping & & & & & -0.18 & 0.43 \\
\hline Workload and Time $\times$ positive coping & & & & & 0.045 & 0.81 \\
\hline Working Environment and Resources $\times$ positive coping & & & & & -0.257 & 0.24 \\
\hline Patient care $\times$ positive coping & & & & & 0.436 & 0.01 \\
\hline Management and Interpersonal Relationship $\times$ positive coping & & & & & -0.054 & 0.73 \\
\hline Nursing Profession and Clinical Duty $\times$ negative coping & & & & & 0.150 & 0.43 \\
\hline Workload \& Time $\times$ negative coping & & & & & -0.468 & 0.01 \\
\hline Working Environment and Resources $\times$ negative coping & & & & & -0.531 & 0.01 \\
\hline Patient Care $\times$ negative coping & & & & & 0.319 & 0.07 \\
\hline Management and Interpersonal Relationship $\times$ negative coping & & & & & -0.327 & 0.06 \\
\hline Adj. $R^{2}$ & \multicolumn{2}{|c|}{$0.36^{*}$} & \multicolumn{2}{|c|}{$0.41^{*}$} & \multicolumn{2}{|c|}{$0.42^{*}$} \\
\hline$R^{2}$-change & \multicolumn{2}{|c|}{$0.36^{*}$} & \multicolumn{2}{|c|}{$0.05^{*}$} & \multicolumn{2}{|c|}{$0.02^{*}$} \\
\hline
\end{tabular}

${ }^{*} P<0.01$ 
Simple regression lines were generated by entering the values of the latent benefit variable $1 \mathrm{SD}$ above and $1 \mathrm{SD}$ below the mean in the simple regression equation that was formed in the previous step. The interaction was then plotted for each of the significant interaction terms to demonstrate effect of coping strategies on the relationship between work stress and job performance.

Plots illustrating the significant moderations are displayed in Figs. 1, 2 and 3. Simple effects tests were conducted to determine whether the slopes significantly differed from zero (Aiken and West, 1991). The significant interaction term for Patient Care $\times$ positive coping strategies indicated that for both more positive coping strategies $(F=92.54$, $p<0.01)$ and less positive coping strategies $(F=36.43$, $p<0.01$ ), increasing levels of work stress associated with decreasing levels of job performance. It also indicated that, with an increase in work stress, participants who used more positive coping strategies reported significantly higher job performance than those who used less positive coping strategies.

The significant interaction term for Workload and Time $\times$ negative coping strategies indicated that for less negative coping strategies, increasing levels of work stress were associated with decreasing levels of job performance $(F=67.49, P<0.01)$ (Fig. 2). For more negative coping strategies, no association was found between levels of work stress and levels of job performance. The significant interaction term for Working Environment and Resources $\times$ negative coping strategies indicated that for both more negative strategies $(F=21.17, P<0.01)$ and less negative strategies $(F=48.17, P<0.01)$, increasing levels of work stress were associated with decreasing levels of job performance (Fig. 2). Furthermore, Figs. 2 and 3 indicated that with an increase in work stress, nurses who used less negative coping strategies reported significantly higher job performance than those who used more negative coping strategies.

\section{Discussion}

The current study was one of the first of its kind to investigate the moderating effects of coping strategies on work stress and job performance among nurses in China. Results indicated that nurses used positive coping strategies more frequently than negative coping strategies. We also found that coping strategies had moderating effects on some of the work stress subscales and job performance.

In order to test the direct and moderating effects of coping strategies on work stress and job performance, a regression analysis was conducted (Table 3 ). First, when work stress variables were used (Model 1, Table 3), three subscales of work stress (i.e., Nursing Profession and Clinical Duty, Workload and Time, and Management and Interpersonal Relationship) had direct negative effects on job performance. These findings were consistent with previous studies that reported that excessive workload, lack of opportunities for promotion, and a lack of respect were major negative predictors of job performance [25].

Second, including negative predictors of job performance into the analysis produced a significant increase in the variance explained in job performance (Model 2, Table 3). This finding supports our expectation that coping strategies would help explain job performance. Consistent with the study by $\mathrm{Lu}$ et al., positive coping strategies were positively related to job performance and

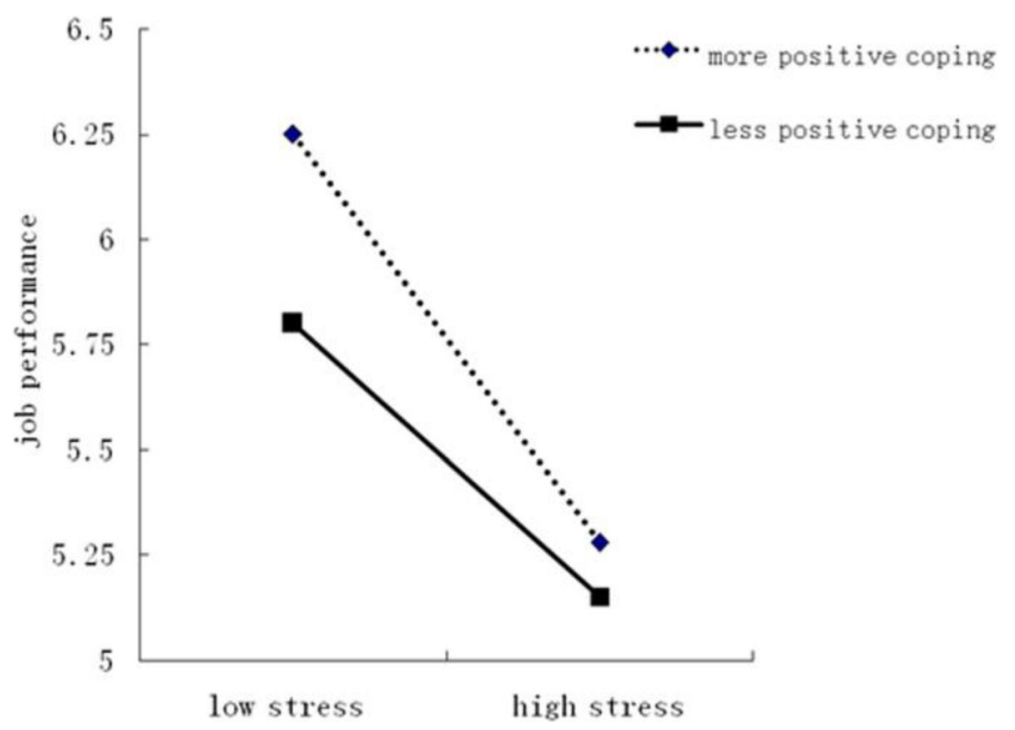

Fig. 1 Moderation of positive coping on patient care stress and job performance 


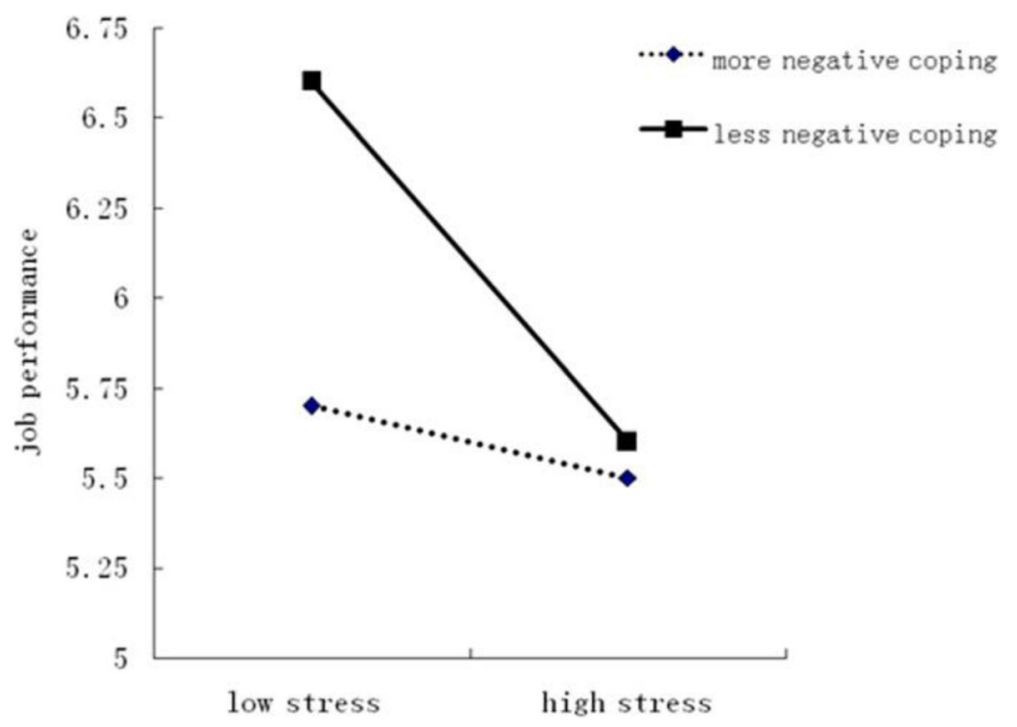

Fig. 2 Moderation of negative coping on workload \& time stress and job performance

negative coping strategies were negatively related to job performance [26].

Furthermore, inclusion of the interaction terms (Stressors $\mathrm{X}$ Coping strategies) accounted for a larger proportion of the explained variance (Model 3, Table 3), indicating that coping strategies had a moderating effect. Specifically, we found that positive coping (e.g. looking for support from family or friends, utilizing others' ways of dealing with similar problems) could reduce or buffer the negative effects of Patient Care on job performance. Negative coping strategies (e.g. procrastinating, relying on others, trying to forget about everything) can strengthen the negative effects of "Workload and Time" and "Working Environment \& Resources" on job performance. Similarly, Atteya found that methods of coping with stress had an impact and exerted an influence on job performance [27]. Taken together; the present findings have significant implications for both managers and nurses in their efforts to improve job performance.

First, since work-related stress is negatively related to job performance, managers should pay more attention to the stress level of the nurses they work with. This study found that Nursing Profession and Clinical Duty was the highest perceived workplace stressor, followed by Workload and Time. Both of these factors were negatively related to job performance. Similarly, a substantial amount of existing research suggested that workload and professional and career issues were primary work stressors for

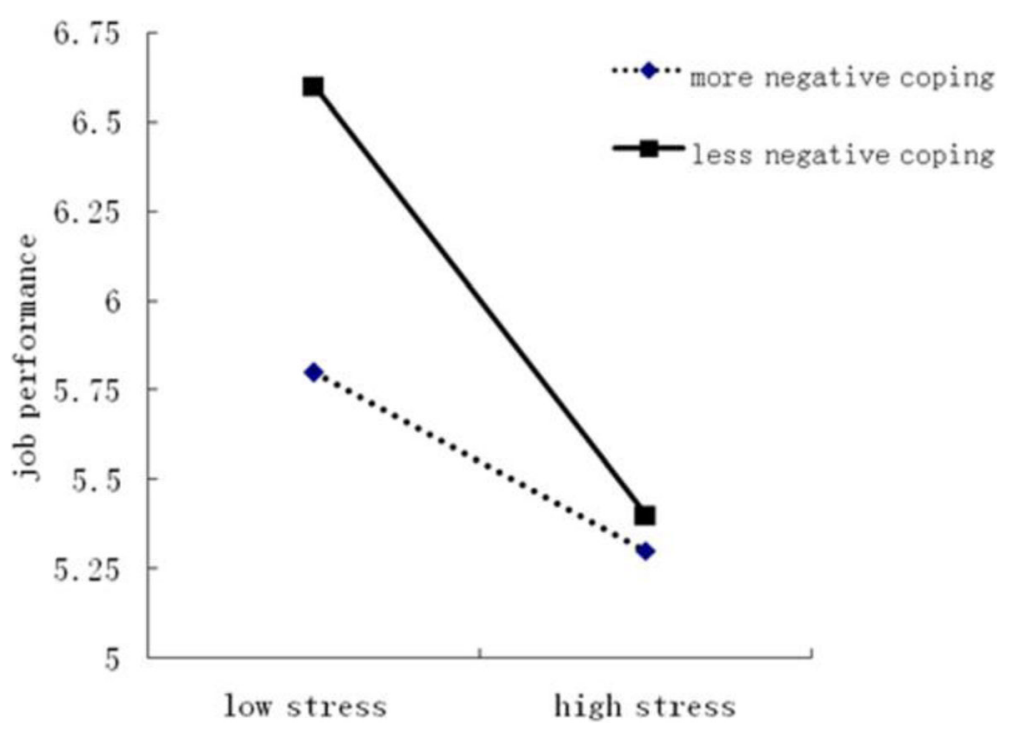

Fig. 3 Moderation of negative coping on working environment \& resources stress and job performance 
nurses in China [23, 28-30]. There are several possible reasons for these findings. First, Chinese nurses have a relatively low social status and experience a lack of recognition by others. They often complain of verbal or physical violence by patients and their families. Second, compared to other health technical workers, nurses have few opportunities for promotion and further study [21]. Furthermore, excessive documentation and shortage of nurses increases nurses' workload [31].

Second, nurses should adopt more positive coping strategies when faced with stress. This study revealed that positive coping strategies could reduce or buffer the negative effect of stress on job performance. Overall, respondents tended to use more positive than negative coping strategies contend with work stress. However, when work stress increased, the usage of positive coping strategies decreased and negative coping strategies increased (Table 2). Therefore organizations should create an environment that encourages workers to use more positive coping strategies when experiencing stress. The managers should investigate and analyze the causes and types of work stress, help nurses to recognize the stress and their own coping styles, and then make detailed stress-reduction plan for nurses on the level of organization. In the meanwhile, managers should carry out training about positive mood management, provide relevant information, and knowledge on stress management for nurses. Besides that, organizations can let nurses think their work is meaningful and beneficial work by developing scientific evaluation system based on key performance indicators.

Thirdly, coping strategies can only partly moderate the effects of work stress on job performance. Furthermore, the moderating effects on job performance were smaller under high stress than under low stress. Consequently, managers should take multiple measures to help nurses to reduce their work stress and in turn to improve the job performance such as creating a safe working environment, establishing adequate infrastructure and other resources, allocating a reasonable workload, and providing support when nurses experience challenges.

\section{Conclusion}

This study was a preliminary attempt to explore the relationship between work stress, coping strategies, and job performance for nurses in China. Results of this study indicate that positive coping strategies moderated the relationship between Patient Care and job performance, while negative coping strategies moderated the relationship between Workload and time and job performance as well as between Working environment and resources and performance. As coping strategies can only moderate the effects of some subscales of work stress on job performance, managers should utilize multiple measures to help nurses to reduce work stress.

\section{Limitations}

Three limitations of this study should be noted. First, performance was obtained from self-reports. Respondents may have underestimated or overestimated the level of their own performance. As we know, job performance can be assessed by objective indicators or subjective indicators. Different hospitals may have different performance evaluation index system, so it is difficult to assess job performance by objective indicators. Subjective assess can be reported by supervisors, colleagues and oneself. Job performance obtained from supervisors or colleagues may also reflect bias in reporting and the anticipated cost is high. So we use self-rated performance take into account the data availability, the accuracy and the cost. We recognized that this self- administration bias might have affected the results. Second, we used a cross-sectional survey, which may limit our ability to identify causal relationships between work stress and job performance. Thirdly, this study was based on a small sample of nurses in tertiary hospitals, which may limit the generalisability of the research findings. University-affiliated hospitals and non-affiliated hospitals may take on different tasks and workload, so a multistage, stratified sampling design was employed to ensure that study data were representative. In this study, two tertiary and two tertiary non-affiliated hospitals were selected. There were 8-10 types of clinical departments in these four hospitals. One sub-department was randomly selected in each kind of clinical department in each hospital.

\section{Acknowledgements}

We are thankful to all the nurses who participated in the study. We are also grateful to heads of the nursing departments of these four hospitals, who have worked closely with the team to ensure the field survey is successfully implemented.

\section{Funding}

This study was funded by Young Seed Foundation of Public Health College of Harbin Medical University.

Availability of data and materials

The data supporting our findings will not be shared, because we have promised respondents not disclose any information in the questionnaire.

\section{Authors' contributions}

$\mathrm{LL}$ was responsible for the study design, data analysis, the drafts and the final manuscript. $H A$ and $L G$, who contributed equally as the first author, were responsible for study design, data collection and data analysis. $\mathrm{HZ}$ provided statistical expertise. XL, ZZ and RP carried out data collection and technical support. LF and TS provided administrative support. All authors read and approved the final manuscript.

Competing interests

The authors declare that they have no competing interests.

Consent for publication

Not applicable. 


\section{Ethics approval and consent to participate}

Respondents were assured that participation in the survey was voluntary, and the return of questionnaires represented informed consent. Institutional Research Board of Harbin Medical University approved the current research and no identifying information was included in the questionnaire. No. HMUIRB20150001.

\section{Publisher's Note}

Springer Nature remains neutral with regard to jurisdictional claims in published maps and institutional affiliations.

\section{Author details}

'Department of Health Management, School of Public Health, Harbin Medical University, Baojian Road 157, Harbin, China. ${ }^{2}$ Second Affiliated Hospital, Harbin Medical University, Harbin, China. ${ }^{3}$ Department of Emergency, Harbin Center for Disease Control and Prevention, Harbin, China.

Received: 17 June 2016 Accepted: 1 June 2017

Published online: 12 June 2017

\section{References}

1. Xianyu Y, Lambert VA. Investigation of the relationships among workplace stressor, ways of coping, and the mental health of Chinese head nurses. Nurs Health Sci. 2006:8:147-55.

2. Nabirye RC, Brown KC, Pryor ER, et al. Occupational stress, job satisfaction and job performance among hospital nurses in Kampala, Uganda. J Nurs Manag. 2011;19:760-8.

3. Voltmer E, Rosta J, Siegrist J, et al. Job stress and job satisfaction of physicians in private practice: comparison of German and Norwegian physicians. Int Arch Occup Environ Health. 2012;85(7):819-28.

4. Saijo Y, Chiba S, Yoshioka E, et al. Job stress and burnout among urban and rural hospital physicians in Japan. Aust J Rural Health. 2013;21(4):225-31.

5. Sun $Y$, Luo ZN, Fang PQ. Factors influencing the turnover intention of Chinese community health service workers based on the investigation results of five provinces. J Community Health. 2013;38(6):1058-66.

6. Cooper $\mathrm{CL}$, Cartwright S. Healthy mind; healthy organization-a proactive approach to occupational stress. Human Relat. 2013;47(4):455-71.

7. Jamal M. Burnout among Canadian and Chinese employees: a cross-cultural study. Eur Manag Rev. 2005;2(3):224-30.

8. Westman M, Eden D. The inverted-U relationship between stress and performance: a field study. Work Stress. 1996;10(2):165-73.

9. Keijsers GJ, Schaufeli WB, Le Blanc PM, et al. Performance and burnout in intensive care units. Work Stress. 1995:9:513-27.

10. Wu YC. Job stress and job performance among employees in the Taiwanese finance sector: the role of emotional intelligence. Soc Behav Personal. 2011;39(1):21-32.

11. Jamal M. Job stress, job performance and organizational commitment in a multinational company: an empirical study in two countries. Int J Bus Soc Sci. 2011;2(20):20-9.

12. Khalid A, Murtaza G, Zafar A, et al. Role of supportive leadership as a moderator between job stress and job performance. Inf Manag Bus Rev. 2012:4(9):487-95.

13. Folkman S, Lazarus KS. An analysis of coping in a middle-aged community sample. J Health Soc Behav. 1980;21(3):219-39.

14. Lazarus RS, Folkman S. Stress, appraisal and coping. New York: SpringerVerlag; 1998

15. Folkman S, Lazarus RS, Gruen RJ, DeLongis A. Appraisal, coping, health status, and psychological symptoms. J Pers Soc Psychol. 1986:50(3):571-9.

16. McCarty WP, Zhao J, Garland BE. Occupational stress and burnout between male and female police officers: Are there any gender differences? Policing: An International Journal of Police Trategies and Management. 2007;30(4):672-91.

17. Gibbons C, Dempster M, Moutray M. Stress, coping and satisfaction in nursing students. J Adv Nurs. 2011;67(3):621-32.

18. Teo STT, Pick D, Newton CJ, et al. Organisational change stressors and nursing job satisfaction: the mediating effect of coping strategies. J Nurs Manag. 2013;21(6):878-87.

19. Williams $L$, Anderson SE. Job satisfaction and organizational commitment as predictors of organizational citizenship and in-role behaviors. J Manag. 1991;17(3):601
20. Bachrach DG, Wang $H$, Bendoly $E$, et al. Importance of organizational citizenship behaviour for overall performance evaluation: comparing the role of task interdependence in china and the USA. Manag Organ Rev. 2007:3(2):255-76.

21. Li XM, Liu YJ. Workplace stressors and exhaustion in nursing. Chin J Nurs. 2000;35(11):645-9.

22. Xie YN. Pilot study on reliability and validity of simple coping style scale. Chin J Clin Psychol. 1998;2:114-5.

23. Frazier PA, Tix AP, Barron KE. Testing moderator and mediator in counseling psychology. J Couns Psychol. 2004;51(1):115-34

24. Aiken LS \& West SG. Multiple regression: Testing and interpreting interactions. Newbury Park, Calif. Sage Publications. 1991.

25. Jehangir M, Kareem N, Khan A, et al. Effects of job stress on job performance and job satisfaction. Interdiscip J Contemp Res Bus. 2011;3(7):453-65.

26. Lu L, Kao SF, Siu OL, et al. Work stressors, Chinese coping strategies, and job performance in the greater China. Int J Psychol. 2010;45(4):294-302.

27. Atteya NM. Role stress measure, methods of coping with stress, and job performance: an exploratory study. J Organ Psychol. 2012;12:30-51.

28. Zhou H, Gong YH. Relationship between occupational stress and coping strategy among operating theatre nurses in China: a questionnaire survey. J Nurs Manag. 2015;23(1):96-106.

29. Cai ZX, Li K, Zhang XC. Workplace stressors and coping strategies among Chinese psychiatric nurses. Perspect Psychiatr Care. 2008;44(4):223-31.

30. Wu H, Sun W, Wang L. Factors associated with occupational stress among Chinese female emergency nurses. Emerg Med J. 2012;29(7):554.

31. Yau SY, Xiao XY, Yin LKL, et al. Job stress among nurses in China. Appl Nurs Res. 2012;25:60-4

\section{Submit your next manuscript to BioMed Central and we will help you at every step:}

- We accept pre-submission inquiries

- Our selector tool helps you to find the most relevant journal

- We provide round the clock customer support

- Convenient online submission

- Thorough peer review

- Inclusion in PubMed and all major indexing services

- Maximum visibility for your research

Submit your manuscript at www.biomedcentral.com/submit
Biomed Central 